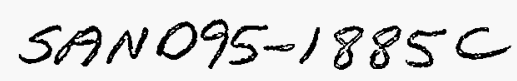

\title{
Novel silicon fabrication process for high-aspect-ratio micromachined parts
}

\author{
James G. Fleming and Carole Craig Barron
}

\author{
Sandia National Laboratories \\ Microelectronics Development Laboratory \\ P.O. Box 5800, Mail Stop 1084 \\ Albuquerque, New Mexico, USA 87185-1084
}

\begin{abstract}
Micromachining is often divided into two categories — bulk and surface micromachining. "Bulk" micromachining generally refers to processes involving wet chemical etching of structures formed out of the silicon substrate and so is limited to fairly large, crude structures. "Surface" micromachining allows intricate patterning of thin films of polysilicon and other materials to form essentially two-dimensional layered parts (since the thickness of the parts is limited by the thickness of the deposited films). In addition to these two types of micromachining there is in fact a third type of micromachining as well, namely "mold" micromachining, in which the part is formed by filling a mold which was defined by photolithographic means. Historically micromachining molds have been formed in some sort of photopolymer, be it with x-ray lithography ("LIGA") or more conventional UV lithography, with the aim of producing piece parts. Recently, however, several groups including ours at Sandia have independently come up with the idea of forming the mold for mechanical parts by etching into the silicon substrate itself.

In Sandia's mold process, the mold is recessed into the substrate using a deep silicon trench etch, lined with a sacrificial or etch-stop layer, and then filled with any of a number of mechanical materiçals. The completed structures are not ejected from the mold to be used as piece parts - rather, the mold is dissolved from around selected movable segments of the parts, leaving the parts anchored to the substrate. Since the mold is recessed into the substrate, the whole micromechanical structure can be formed, planarized, and integrated with standard silicon microelectronic circuits before the release etch. In addition, unlike surfacemicromachined parts, the thickness of the molded parts is limited by the depth of the trench etch (typically 10-50 $\mu \mathrm{m}$ ) rather than the thickness of deposited polysilicon (typically $2 \mu \mathrm{m}$ ). The capability of fabricating thicker (and therefore much stiffer and more massive) parts is critical for motion-sensing structures involving large gimballed platforms, proof masses, etc. At the same time, the planarized mold technology enables the subsequent fabrication of features (for example flexible springs and flexures) - much finer than those possible with bulk processes.
\end{abstract}

\section{KEY WORDS}

Silicon micromachining, microelectromechanical systems, bulk micromachining, surface micromachining, mold micromachining, LIGA, reactive ion etching (RIE), silicon fabrication, integration.

\section{INTRODUCTION}

Micromachining is often divided into two categories — bulk and surface micromachining - but in fact there are three distinct types of silicon micromachining, the Sandia process being in the third category: mold micromachining. In order to highlight the merits of the Sandia mold process, it is useful first to consider the strengths and weaknesses of the other micromachining approaches. Note that the references given here are only examples and are not by any means intended to be a complete survey of the literature.

\section{1,1 Bulk micromachining}

The term "bulk" micromachining literally refers to the process of making a mechanical structure out of the bulk material (i.e. the single-crystal silicon substrate). Generally the mechanical structure is formed either by doping-selective ${ }^{1}$ or crystallogaphic $^{2}$ wet chemical etching. These processes are relatively large-scale and crude compared to the sub-micron photolithographic processes common in microelectronic fabrication, with dimensional variations on the microns to hundreds-of-microns scale. A subcategory of bulk micromachining which offers finer dimensional control is dry etching of mechanical structures - 


\section{DISCLAIMER}

This report was prepared as an account of work sponsored by an agency of the United States Government. Neither the United States Government nor any agency thereof, nor any of their employees, make any warranty, express or implied, or assumes any legal liability or responsibility for the accuracy, completeness, or usefulness of any information, apparatus, product, or process disclosed, or represents that its use would not infringe privately owned rights. Reference herein to any specific commercial product, process, or service by trade name, trademark, manufacturer, or otherwise does not necessarily constitute or imply its endorsement, recommendation, or favoring by the United States Government or any agency thereof. The views and opinions of authors expressed herein do not necessarily state or reflect those of the United States Government or any agency thereof. 


\section{DISCLAIMER}

Portions of this document may be illegible in electronic image products. Images are produced from the best available original document. 
again, the part is formed from the single-crystal silicon substrate itself. ${ }^{3}$ One of the major advatages of bulk micromachining is that it is relatively easy to fabricate large masses (for accelerometers, for example), but, on the other hand, delicate, sensitive suspensions are difficult to realize. Also, bulk micromachining processes are not particularly compatible with electronics, simply because they aren't planar.

\subsection{Surface micromachining}

Surface micromachining uses the planar fabrication techniques common to the microelectronic circuit fabrication industry to manufacture micromechanical devices. The standard building-block process consists of depositing and photolithographically patterning alternate layers of low-stress polycrystalline silicon and sacrificial silicon dioxide. As shown in Figure 1, holes etched through the sacrificial layers provide anchor points between the mechanical layers and to the substrate. At the completion of the process, the sacrificial layers, as their name suggests, are selectively etched away in hydrofluoric acid (HF), which does not attack the silicon layers. The result is a construction system consisting of one layer of polysilicon which provides electrical interconnection and one or more independent layers of mechanical polysilicon which can be used to form mechanical elements ranging from a simple cantilevered beam to complex systems of springs, linkages, mass elements, and joints. Because the entire process is based on standard integrated-circuit fabrication technology, hundreds to thousands of devices can be batch-fabricated on a single six-inch silicon substrate.

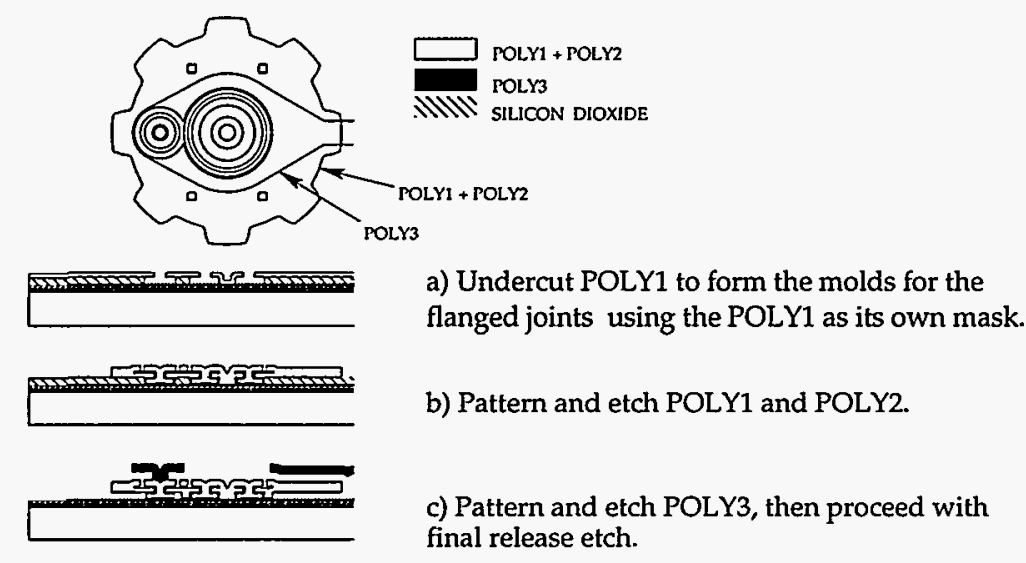

Figure 1: Example surface-micromachining process. ${ }^{4}$ These are cross-sections through essential elements of the Sandia microengine gear and joints taken at three stages of completion.

Because surface micromachining takes advantage of the advanced manufacturing processes developed in the microelectronics fabrication industry, it offers the same high degreee of dimensional control found in electronic integated circuit fabrication, and is the micromachining method most compatible with integrated electronics. ${ }^{5}$ The planarity which makes surface-micromachined parts relatively easy to integrated with microelectronics, however, is also the major limitation of surface micromachining - that is, surface-micromachined parts are essentially two-dimensional (since the thickness of the parts is limited by the thickness of the deposited films), and therefore relatively light and compliant.

\subsection{Mold micromachining}

We are using "mold micromachining" to refer to micromachining processes in which a mold is formed in some way and then the mechanical structure is made by filling that mold. The principal advantage of all mold micromachining processes are that they make it possible to fabricate high-aspect-ratio parts (i.e. thick relative to surface dimensions). Mold micromachining has generally been used to manufacture piece parts (e.g. gears, etc.), although micromachined structures formed with thick photo-sensitive polymer molds have also been integrated with previously fabricated electronic circuits. Variations on the mold concept include, on the one hand, the well-known "LIGA" process, in which lithography is used directly to form a photoresist mold, and, on the other hand, the Berkeley "HEXSIL" process, the Michigan "trench-refill" process, and the Sandia mold process, in which the mold is formed by etching into the silicon substrate. 


\subsection{1 "LIGA" and "LIGA-like" processes}

"LIGA" is a German acronym which refers to "lithography, electroplating, and injection molding". The original LIGA process, while it achieves impressive aspect ratios, ${ }^{6}$ has only seen scattered application because it requires specialized x-ray lithography equipment. "LIGA-like" processes include ones where the more common UV-exposed photoresist is used instead. These "LIGA-like" processes allow fabrication of thicker parts than can be made using surface micromachining, but are generally limited to much less extreme aspect ratios than the original LIGA process. ${ }^{7}$ Both the original LIGA process and the "LIGA-like" processes lend themselves primarily to the fabrication of piece parts which require subsequent assembly into a microelectromechanical system.

\subsubsection{Silicon mold processes}

The basic concept behind all three of the silicon mold processes described in this section is that the mold for a micromechanical part is formed by etching into the silicon substrate (Figure 2). All three processes thus take advantage of the fact that, by etching a high-aspect-ratio mold (that is, one which is much deeper than it is wide) and filling it with a conformal thin film, one can form a mechanical structure that is much thicker than the maximum thickness of the deposited film itself.

\subsubsection{Berkeley "HEXSIL" process}

The so-called "HEXSU" process, developed at UC Berkeley, ${ }^{8}$ consists of forming a mold by sawing or reactive-ion-etching into the silicon substrate, lining the mold with deposited oxide, and then filling it with polysilicon. The principal aim of the process is, like "LIGA," to fabricate a reusable mold for piece parts. Since the molded "HEXSIL" part is recessed into the silicon substrate, it is possible to integrate a "HEXSIL" part with electronics, although to do so the Berkeley concept requires bonding another single-crystal substrate on top of the mold.

\subsubsection{Michigan "trench-refill" process}

Selvakumar and Najafi at the University of Michigan have integrated a silicon mold process with bulk micromachining?. Again the etched silicon mold is lined with deposited oxide and then filled with polysilicon. The substrate is then removed with a wet chemical etch to release the molded part.

\subsubsection{The Sandia mold micromachining process}

The independently invented Sandia mold process is similar to the "HEXSIL" and Michigan processes in that the mold is formed by etching into the substrate. The goal of the process, however, is monolithic integrability of the molded high-aspect-ratio parts with surface micromachining and microelectronics, and the process flows consequently differ in important respects.

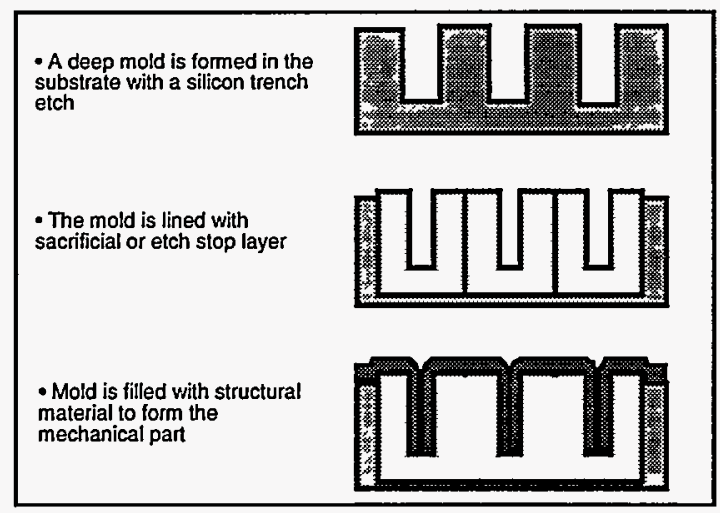

Figure 2. Generalized silicon mold process. 


\section{THE SANDIA MOLD MICROMACHINING PROCESS FLOW}

The first step in the Sandia mold process is to etch the mold pattern into the substrate using a "deep trench" reactive-ionetching process. The silicon pattern is then transformed into a mold in one of several ways. For example, if the structure will be formed of polysilicon and released in HF, the mold is oxidized at this point. It is also possible (as in the Michigan process) to remove the silicon mold by wet etching the silicon, in which case the mold is completed instead by depositing an etch stop layer. The commonality in both cases is that, in the end, the mold-micromachined parts are anchored to the substrate and released in place, like surface-micromachined parts - the mold is not reused. After the mold is formed, it can be filled with any of a number of materials, including most of the thin films common in the semiconductor industry (doped or undoped polysilicon, silicon nitride, CVD tungsten, etc.), as well as plated metals. The wafer is then planarized by an etchback or chemical-mechanical polish (CMP) process. At this point, assuming materials compatibility, it can be taken through a surface-micromachining or electronic integrated circuit fabrication process (or both). Once all the processing is complete, the mechanical parts are released so that they are free to move relative to the substrate. Note that many variations on this basic concept are possible - we give two very different examples below.

\section{AN EXAMPLE OF A STRUCTURE FABRICATED IN THE SANDIA MOLD PROCESS:}

\section{A THICK TUNGSTEN PLATE}

To fabricate a molded tungsten plate to be used as the proof mass for a micromachined accelerometer, we oxidized a trenchetched mold, and filled it with CVD tungsten. Figure $3 \mathrm{a}$ shows the etched mold after oxidation. In order to form this mold, we used a Cl $2 / \mathrm{HBr} / \mathrm{O}_{2}$ etch chemistry in an electron cyclotron resonance $(\mathrm{ECR})$ reactive-ion etcher to etch pillars roughly one micron in diameter and over twenty microns tall out of the silicon substrate. We then oxidized the wafer to an oxide thickness of 1.5 microns. Finally, we filled the mold with chemical-vapor deposited (CVD) tungsten and planarized the wafer with CMP. Figure $3 \mathrm{~b}$ shows the finished proof mass ready to be integrated with surface-micromachined suspension springs and sense contacts before being released in a hydrofluoric acid etch.

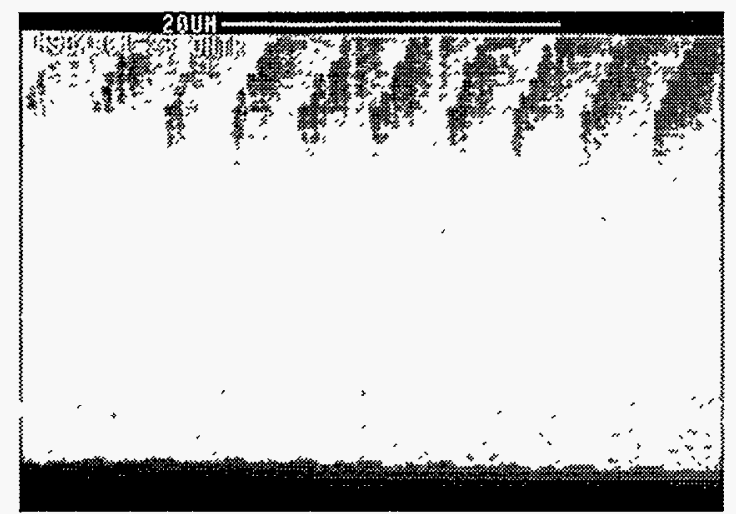

Figure 3a: Silicon dioxide mold for accelerometer proof mass.

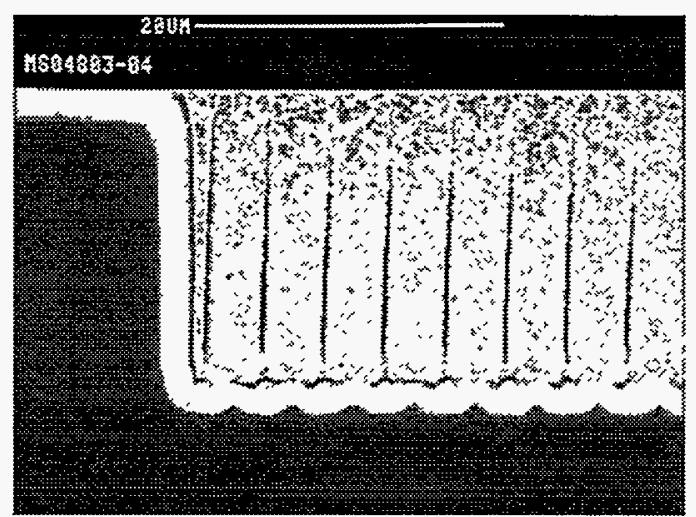

Figure 3b: $\quad$ Molded tungsten proof mass.

\section{A SECOND EXAMPLE OF A STRUCTURE FABRICATED IN THE SANDIA MOLD PROCESS: A SILICON NITRIDE "TEETER-TOTTER"}

In order to fabricate a silicon nitride / silicon dioxide "teeter-totter" to serve as the platform for an atomic-force microscope (AFM), we lined a trench-etched silicon mold similar to the one described above with deposited silicon nitride, then filled it with silcon dioxide and released the structure from the substrate with a $\mathrm{KOH}$ silicon etch. Figure $4 \mathrm{a}$ shows a finished platform; Figure $4 \mathrm{~b}$ is a close-up of a piece removed from the surface of the platform, showing the honeycomb-like structure formed by the nitride and oxide layers. Note that in this case the silicon dioxide is used as a structural material, and the silicon as the sacrificial layer, the reverse of the usual case. 


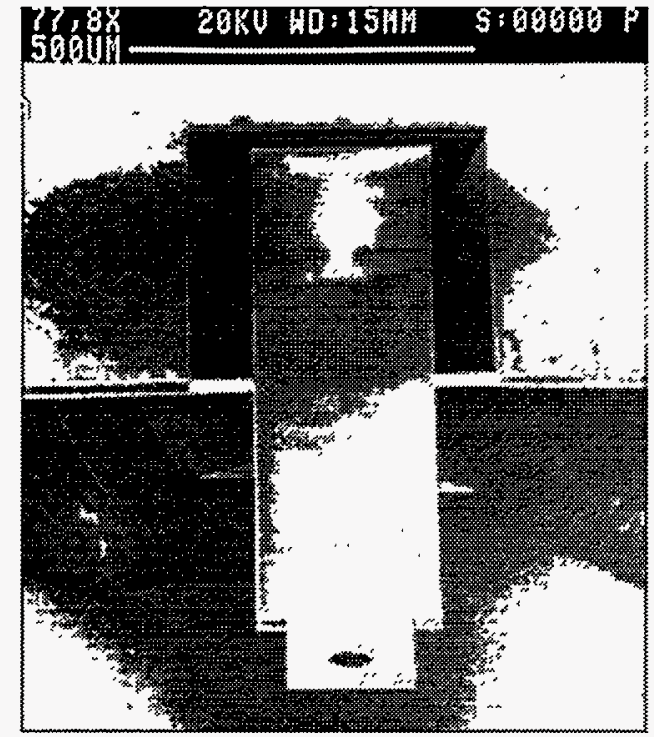

Figure 4a. Finished AFM platform

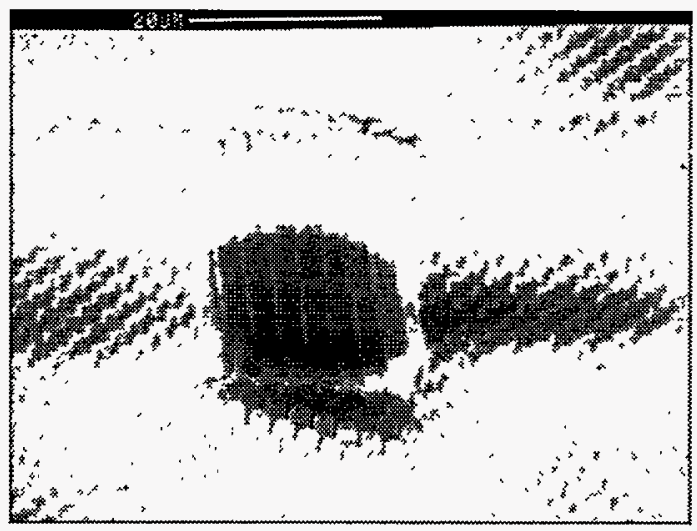

Figure 4b. Detail of AFM platform shown in Figure 4a. The piece in the center of the SEM photo has been removed to show the honeycomb structure.

\section{INTEGRABILITY WITH SURFACE MICROMACHINING AND MICROELECTRONICS}

The foregoing examples demonstrate the flexiblity and generality of the Sandia mold micromachining approach. In each case, however, the common factor is that these high-aspect-ratio structures are countersunk into the substrate and are therefore integrable with subsequent surface-micromachining and microelectronic fabrication processes. We anticipate that such an integrated mold micromachining/surface micromachining/electronics process will offer high-aspect-ratio structures that can be batch-fabricated and monolithically integrated into complex microelectromechanical systems.

\section{ACKNOWLEDGMENTS}

The authors would like to acknowledge the staff of the Microelectronics Development Laboratory, without whom this work would have been impossible. This work was performed at Sandia National Laboratories and supported by the U. S. Department of Energy under contract \# DE-AC04-94AL85000.

\section{NOTES AND REFERENCES}

1. L. Spangler and K. D. Wise, "A New Silicon-on-glass Process for Integrated Sensors," IEEE Sensor and Actuator Workshop, Hilton Head, SC, pp. 140-142, June, 1988.

2. K. E. Petersen, "Silicon as a Mechanical Material," Proc. IEEE, vol. 70, no. 5, pp. 420-457, May, 1982.

3. Examples of bulk micromachining using dry etching:

W.H. Juan and S. W. Pang, "A Novel Etch-Diffusion Process for Fabricating High Aspect Ratio Si Microstructures," 8th International Conference on Solid-State Senosrs and Actuators, Stockholm, Sweden, June 25-29, 1995, pp. 560563.

Y. Xu, S. A. Miller, and N. C. MacDonald, "Microelectromechanical Scanning Tunneling Microscope", 8th International Conference on Solid-State Senosrs and Actuators, Stockholm, Sweden, June 25-29, 1995, pp. 640-643.

K. A. Shaw, Z. L. Zhang, and N. C. MacDonald, "SCREAM I: A single mask, single-crystal silicon process for microelectromechanical structures,” Tech. Digest, IEEE Solid-State Sensor and Actuator Workshop, 1993. 
4. Figure courtesy of J. J. Sniegowski. The Sandia tri-level polysilicon surface-micromachining technology has been described in

J. J. Sniegowski and E. J. Garcia, "Microfabricated Actuators and their Application to Optics," Proc. SPIE vol. 2383, pp. 46-64.

For an earlier review of surface micromachining:

R. T. Howe, "Surface micromachining for microsensors and microactuators," J. Vac. Sci. Technol. B, vol. 6, no. 6, pp. 1809-1813, 1988.

5. T. A. Core, W. K. Tsang, and S. J. Sherman, "Fabrication technology for an integrated surface-micromachined sensor," Solid State Technology, vol. 36, no. 10, pp. 39+, 1993.

6. H. Guckel, T. Earles, J. Klein, D. Zook, and T. Ohnstein, "Electromagnetic Linear Actuators with Inductive Position Sensing for Micro Relay, Micro Valve and Precision Positioning Applications," 8th International Conference on SolidState Senosrs and Actuators, Stockholm, Sweden, June 25-29, 1995, pp. 324-327.

E. W. Becker, W. Ehrfeld, P. Hagman, A. Maner, and D. Münchmeyer, Microelectronic Engineering, vol. 4,) pp. 35-56, 1986.

7. Examples of "LIGA-like" processes:

M. W. Putty and K. Najafi, "A Micromachined Vibrating Ring Gyroscope," 1994 Solid-State Sensor and Actuator Workshop, Hilton Head, SC June 13-16, 1994, pp. 213-220.

A. B. Frazier and M. G. Allen, "Uses of Electroplated Aluminum in Micromachining Applications," 1994 Solid-State Sensor and Actuator Workshop, Hilton Head, SC June 13-16, 1994, pp. 90-94.

8. C. G. Keller and R. T. Howe "Hexsil Bimorphs for Vertical Actuation," pp. 99-102, and "Nickel-Filled HEXSIL Thermally Actuated Tweezers," pp. 376-379, 8th International Conference on Solid-State Senosrs and Actuators, Stockholm, Sweden, June 25-29, 1995.

C. Keller and M. Ferrari, "Milli-Scale Polysilicon Structures," 1994 Solid-State Sensor and Actuator Workshop, Hilton Head, SC June 13-16, 1994, pp. 132-137.

9. A. Selvakumar and K. Najafi, "High Density Vertical Comb Array Microactuators Fabricated Using a Novel Bulk/Polysilicon Trench Refill Technology," 1994 Solid-State Sensor and Actuator Workshop, Hilton Head, SC June 13-16, 1994, pp. 138-141.

\section{DISCLAIMER}

This report was prepared as an account of work sponsored by an agency of the United States Government. Neither the United States Government nor any agency thereof, nor any of their employees, makes any warranty, express or implied, or assumes any legal liability or responsibility for the accuracy, completeness, or usefulness of any information, apparatus, product, or process disclosed, or represents that its use would not infringe privately owned rights. Reference herein to any specific commercial product, process, or service by trade name, trademark, manufacturer, or otherwise does not necessarily constitute or imply its endorsement, recommendation, or favoring by the United States Government or any agency thereof. The views and opinions of authors expressed herein do not necessarily state or reflect those of the United States Government or any agency thereof. 